\title{
A evolução das redes sociais na execução de projetos em um agrupamento escolar
}

\author{
The evolution of social networks in the execution \\ of projects in a school group
}

\author{
Fernando Cardoso SOUSA ${ }^{1}$ (iD) 0000-0002-4103-2469 \\ lleana Pardal MONTEIRO2 ID $_{0000-0002-8917-8918}$ \\ José Pires BICA $^{3}$ iD) 0000-0001-6550-2659
}

\section{Resumo}

Este artigo compara as redes sociais existentes antes e depois da execução de projetos baseados no método de resolução criativa de problemas, adaptado para funcionar com grupos grandes. A apresentação do caso, desenvolvido junto a um agrupamento escolar, inclui a preparação e execução do fórum, a implementação de projetos de inovação e a medida das redes de comunicação existentes nas equipes, antes e depois da realização dos projetos. Os resultados comprovam a eficácia da metodologia para o estabelecimento de projetos de inovação. A análise das redes sociais permite compreender melhor o que se passa durante a execução dos projetos pelas equipes, seja em termos de liderança, seja quanto à evolução da rede de relações de trabalho. Do estudo deste caso, ressaltam características desejáveis para a melhoria do referido método de intervenção e para a construção de modelos de análise da execução dos projetos, a partir da evolução das redes sociais.

Palavras-chave: Criatividade; Inovação organizacional; Rede social.

\footnotetext{
Abstract

This article compares existing social networks before and after the execution of projects generated by the use of creative problem-solving method, adapted to work with large groups. The presentation of the case, with a school grouping,

1 Universidade do Algarve, Faculdade de Economia, Centro de Investigação do Espaço e Organizações. Estr. da Penha 139, 8005-139, Faro, Portugal. Correspondência para/Correspondence to: F. C. SOUSA. E-mail: <cardoso_sousa@hotmail.com>.

2 Universidade do Algarve, Escola Superior de Gestão, Hotelaria e Turismo, Curso de Gestão Hoteleira. Faro, Portugal.

3 Instituto Superior Dom Afonso III, Centro de Investigação das Ciências da Educação e Formação, Curso de Educação Física e Desporto. Loulé, Portugal.

$\boldsymbol{\nabla v} \mathbf{v}$

Como citar este artigo/How to cite this article

Sousa, F. C., Monteiro, I. P., Bica, J. P. (2018). A evolução das redes sociais na execução de projetos em um agrupamento escolar. Estudos de Psicologia (Campinas), 35(3), 265-274. http://dx.doi.org/10.1590/1982-02752018000300005
} 
includes the preparation and execution of the forum, the implementation of the innovation projects and the measurement of existing small-world networks within teams, before and after the projects were carried out. The results support the effectiveness of the methodology in the establishment of innovation projects. The analysis of networks allows a better understanding of what happens during the execution of the projects by the teams, in terms of leadership and evolution of work connections. From this case, we highlight desirable characteristics for the improvement of the present method of intervention, and for the construction of models of analysis of project execution, from the evolution of small-world networks.

Keywords: Creativity; Organizational innovation; Social networking.

A orientação deste estudo baseia-se na tomada de decisão em grupo, tendo como quadro de referência as abordagens de resolução criativa de problemas em grupos pequenos, desenvolvidas por investigadores tais como Basadur (1987), Isaksen e Treffinger (2004), Puccio, Firestien, Coyle e Masucci (2006). Este estudo é também sensível às análises que criticam a eficiência dos métodos baseados no brainstorm na produção de ideias geradoras de valor, como Paulus e Brown (2003).

Na condição de investigadores e práticos, os autores da presente pesquisa têm dedicado tempo e esforços no desenvolvimento de uma metodologia adequada às necessidades da realidade e do contexto portugueses, principalmente: o tempo limitado que as organizações podem despender em reuniões de grupo para tomada de decisão; a simplicidade de execução, possibilitando a sua apropriação pela organização objeto de intervenção; e uma metodologia essencialmente orientada para a ação e não apenas para a produção de ideias. Essas exigências não devem pôr em causa os resultados, em termos de vinculação emocional e orientação para o produto, nem comprometer a estabilidade da composição do grupo. Há que ter em conta que a redução do tempo das reuniões pode comprometer a eficácia, se não forem adotados procedimentos específicos (Sousa, Monteiro, \& Pellissier, 2009).

Assim, considerou-se útil a criação de um método de intervenção rápida, assentado em estudos previamente realizados com a metodologia de resolução criativa de problemas em grupos pequenos (Sousa, Monteiro, Walton, \& Pissarra, 2014), reduzindo para quatro horas a duração das reuniões, sem perda de eficácia, de modo a impedir que um intervalo demasiado longo durante as sessões pudesse alterar a composição dos grupos. Esse método permitiu trabalhar em vários contextos, com grupos pequenos, na implementação de projetos de inovação (Sousa et al., 2009), ou no ensino por projetos (Sousa, Mendes, \& Monteiro, 2012).

Frente à necessidade de incluir mais stakeholders no processo de decisão, representando o conhecimento, os poderes existentes e aqueles que podem ser afetados pelas decisões, os grupos tornam-se demasiado grandes. Com efeito e, embora se tenha usado a metodologia de Resolução Criativa de Problemas (RCP) com grupos de cerca de vinte ou mais pessoas, constatou-se que ela não se adequava a tais números. Decidiu-se, por isso, preparar um protocolo que permitisse trabalhar com grupos grandes, mantendo a duração de quatro horas e o máximo de benefícios dos métodos de trabalho com grupos maiores. Foram feitas experiências bem sucedidas com estudantes (Sousa, Monteiro, \& Pellissier, 2015) e com comunidades (Sousa, Monteiro, Gaspar, \& Castelão, 2016), o que proporcionou aos pesquisadores a preparação necessária para trabalhar com outros tipos de organizações em que um exemplo de intervenção constituísse o objetivo do trabalho.

Esta descrição também utiliza a medida da evolução das redes sociais, anteriormente utilizada com estudantes (Sousa et al., 2015), a fim de melhor perceber o que se passa durante a execução dos projetos, em termos de liderança e evolução das redes de trabalho. Assim, este artigo compara as redes sociais existentes antes e depois da execução de projetos baseados no método RCP, adaptado para grupos grandes, num agrupamento escolar que pretendia desenvolver um projeto conjunto para a melhoria do ensino. 


\section{Adaptação do método para o trabalho com grupos grandes}

A investigação sobre métodos de tomada de decisão em grupos grandes, com a intenção de trazer inovação e mudança às organizações e comunidades por meio do envolvimento de muitas pessoas no processo de decisão, está bem documentada. Kurt Lewin, Douglas McGregor, Mary Parker Follet, Fred Emery e Eric Trist são apenas alguns dos nomes considerados por Weisbord (2012) numa extensa revisão dos fundamentos teóricos dos métodos de grupos grandes, também descritos por Bunker e Alban (2006).

Esses métodos destinam-se a intervenções em grupos com um número de participantes igual ou superior a 30 elementos, variando na duração (entre um e três dias), tipo de problemas adequados, forma de articulação entre a gestão e o grupo, e dimensão ideal do grupo (entre 30 e 150 pessoas, sendo a dimensão ideal entre 70 e 80 pessoas, por se considerar que é com esse número que se consegue a diversidade suficiente). Os métodos possuem sequências próprias, mas, no geral, começam por solicitar aos subgrupos (sempre grupos de oito participantes, à volta de mesas de 1,5m de diâmetro) uma visão do futuro desejável, o que é relativamente fácil de obter. Depois, seguese a fase do diagnóstico do presente, quando se aproveita para conhecer melhor a história da organização e para criar a tensão necessária à definição dos obstáculos para atingir esse ideal. Por último, são definidas as direções estratégicas, as ações necessárias e o cronograma, assim como as sessões de seguimento.

Dado o envolvimento de todos os intervenientes no mesmo local e ao mesmo tempo, os métodos com grupos grandes permitem que uma mudança ocorra num ritmo muito mais rápido que o normal. Também promovem uma hierarquia plana e fornecem oportunidades para a gestão de conflitos, estabelecendo o foco no terreno comum a ser definido pelas várias partes, em vez de se acentuarem as diferenças.

Sendo a duração das sessões, nos métodos de grupos grandes, incompatível com o escasso tempo disponível para os fóruns, a presente pesquisa buscou modelos já trabalhados em estudos anteriores acerca de procedimentos de resolução de problemas em grupos com menos de 12 elementos, também associados a medidas de compromisso (Sousa et al., 2014). A experiência foi feita com estudantes do ensino superior (Sousa et al., 2015), em apenas três horas.

Trata-se de um modelo de quatro passos: definir o objetivo; definir o problema; planejar a ação; e executar a ação. A Definição do Objetivo tem lugar durante uma "pré-consulta" com o presidente do fórum, quando ficam definidos a composição do grupo e os detalhes logísticos. Durante a Definição do Problema, o grupo enumera todas as barreiras possíveis para alcançar o objetivo e, em seguida, o presidente do fórum seleciona a definição do problema a trabalhar. Durante o Planejamento da Ação, o grupo começa por listar todas as ações necessárias para resolver o problema definido e, em seguida, coloca-as por ordem de execução. Para cada tarefa, no "como fazer?", a pergunta é definida de forma a incluir todas as ações necessárias para superar as resistências à implementação. Em coordenação com o responsável, cada tarefa é atribuída a uma subequipe, que define os prazos e a entidade responsável pela avaliação do resultado. O último passo - a Ação - tem início após a sessão de planejamento.

\section{Redes Sociais}

Revendo a evolução ocorrida desde que Stanley Milgram surgiu com a designação de "pequenos mundos" e o fenômeno dos "seis graus de separação", necessários para ligar todos os estranhos numa rede, Uzzi e Spiro (2005) definiram uma rede social como uma estrutura de uma rede de comunicação densamente agrupada e com ligações curtas entre os seus membros (ou seja, o número médio de passos que leva cada ator da rede para atingir os outros). Como explicado por Kastelle e Steen (2010), estudar essas conexões de forma empírica confere um papel central à análise de redes sociais, por meio de gráficos de simulação aleatória, ou outras técnicas estatísticas 
que permitam compreender a relação curvilinear entre alguns dos índices das redes e a produtividade ou a inovação (demasiada comunicação consome tempo de trabalho). Essa análise se dá pelo exame de dimensões tais como a extensão do caminho de ligação (path-lenght), a densidade, a distância geodésica, a intermediação e a intermediação normalizada. A extensão do caminho de ligação é o número médio de passos que levam os atores da rede para se alcançarem uns aos outros. A densidade representa a percentagem média dos laços existentes sobre o total de conexões possíveis. A distância geodésica representa as distâncias entre os nodos da rede, isto é, para cada par de nodos pode ser determinado o caminho mais curto; em nível da rede, a distância geodésica refere-se ao número médio de caminhos entre os nodos. A intermediação (betweenness) calcula a frequência com que o ator se situa nos caminhos mais curtos (geodésicos) entre todos os outros atores da rede, ou seja, mede a posição do sujeito e da medida em que outras pessoas dependem dele para ter acesso a informações ou se conectar a outro. A intermediação normalizada (nBetweenness) é obtida pela divisão entre a intermediação simples e o seu valor máximo, e representa a medida em que, em média, um nodo está ligado a outros nodos, que não estão ligados uns aos outros, expressa em percentagem.

A essência de uma estrutura de rede é a ligação entre clusters densos por eventuais laços, que servem de ponte e que fornecem a tensão necessária entre o agrupamento e a transição, necessários para benefícios criativos. Como Fleming e Marx (2006) explicam, o simples cluster, sozinho, pode não ser suficiente para a criatividade e pode até ser prejudicial devido à superabundância de conexões, algumas das quais podem ser redundantes e favorecer o isolamento dos grupos em relação a uma informação nova. No entanto, a coesão de grupos, embora prejudicial para a produção de ideias quando a densidade de laços diretos e indiretos é muito grande, pode ajudar as fases subsequentes de desenvolvimento e difusão de inovações (Ahuja, 2000). Os laços diretos referem- laços indiretos referem-se à ligação de dois nodos através de um ou mais nodos.

Os clusters são ligados por agentes - os guardiões (gatekeepers), ou corretores (brokers) que, de acordo com Burt (1992, 2004), têm acesso mais cedo a uma diversidade maior de informações e são centrais para traduzir essa informação para todos os grupos. Esses corretores podem ajudar as ideias a viajar entre os buracos estruturais (lacunas de fluxos de informação), ou entre clusters, e a acumular valor em cada transição, através de um processo de redescoberta e adaptação das diversas restrições e requisitos que podem transformar uma ideia numa inovação importante para a organização (Ahuja, 2000).

\section{Método}

Aqui se descreve o contexto e o procedimento utilizado no caso do Agrupamento de Escolas Pinheiro e Rosa para se poder comparar as redes sociais existentes antes e depois da execução dos projetos, num agrupamento escolar que pretendia desenvolver um projeto conjunto para a melhoria do ensino.

\section{Participantes}

O parque escolar da rede pública do Concelho de Faro, no Sul de Portugal, é atualmente constituído por cinco agrupamentos de escolas, sendo um deles o Agrupamento de Escolas Pinheiro e Rosa. Esse Agrupamento, criado e homologado em 24 de abril de 2013, é uma unidade organizacional dotada de órgãos próprios de administração e gestão, sendo constituído pela integração de nove escolas de diferentes níveis e ciclos de ensino.

No ano letivo de 2015/2016, a população escolar era constituída por 2.136 alunos, distribuídos pelo ensino pré-escolar (8\%), $1^{\circ}$ ciclo (35\%), $2^{\circ}$ ciclo (14\%), $3^{\circ}$ ciclo (23\%) e ensino secundário (20\%). O corpo docente contava com 208 elementos, majoritariamente do quadro (condição para sua estabilidade) e do sexo feminino, com mais de dez 
anos de serviço. O corpo não docente contava com 118 elementos, com idade predominante entre 50 e 59 anos.

As seis escolas do $1^{\circ}$ ciclo do ensino básico eram constituídas, na sua totalidade, por 641 alunos distribuídos em 37 turmas, e por 43 professores. A escola $n^{\circ} 5$ (Vale de Carneiros) e a da Lejana apresentavam o maior número de turmas (9), ao passo que a escola da Bordeira contava com o menor número de turmas (2), seguida por Santa Bárbara de Nexe (3), Estoi (5) e Conceição (6).

Os professores do $1^{\circ}$ ciclo tinham diversas iniciativas no plano anual de atividades e no plano de trabalho das turmas. No entanto, nunca tinham tido a oportunidade de trabalhar no conjunto das seis escolas.

\section{Procedimentos}

A sessão de resolução criativa de problemas, antecedida de uma reunião de preparação com a direção do Agrupamento, contou com a presença de 50 participantes da comunidade escolar das seis escolas do $1^{\circ}$ ciclo, sendo dois assistentes operacionais (pessoal não docente), cinco encarregados de educação e 43 professores. A direção do agrupamento lançou o desafio aos participantes que se materializou no objetivo dessa sessão de trabalho: gerar projetos relativos à melhoria da aprendizagem dos alunos do $1^{\circ}$ ciclo.

Os participantes foram distribuídos aleatoriamente por sete grupos, cada qual com um coordenador/facilitador nomeado pelos seus pares. Após algum tempo de discussão foram identificados 14 problemas, modificados para figurarem como desafios, mediante a inclusão da expressão Quais os passos a dar para...? (dois por grupo). Nessa fase, foi solicitado a cada grupo que selecionasse apenas um problema. Assim, dos 14 problemas iniciais, surgiram sete, selecionados pelo diretor do Agrupamento. As equipes conceberam listas de projetos de solução para os problemas, dos quais foram selecionados os seguintes: (1) Desenvolver o autoconhecimento e valorizar as aprendizagens; (2) Fomentar a coadjuvação voluntária; (3) A biblioteca vem à escola; (4) Gerar encontros de leitura; (5) Avaliar a leitura oral; (6) Melhorar hábitos de leitura; (7) Cumprir apoio educativo aos alunos sem prejuízo das substituições.

Após o intervalo, os diferentes participantes foram convidados a se reagrupar em torno dos sete projetos, de acordo com sua preferência pessoal. O projeto (2) Fomentar a coadjuvação voluntária não teve participantes, tendo sido abandonado. Pediu-se então aos novos grupos, após designarem os facilitadores, que estabelecessem planos de ação a serem implementados até o final de 2016.

A sessão teve a duração de três horas, e quase todas as tarefas foram realizadas com êxito. Na segunda parte da sessão, quando já estavam constituídas as equipes de projeto, foi passado o questionário de redes sociais, já utilizado na investigação relatada em Sousa et al. (2015), em que se perguntava a cada elemento, numa escala de 0 (nunca) a 3 (frequentemente), a frequência de contato de trabalho com os restantes. Esse questionário foi remetido a cada participante, no final do projeto, via correio eletrônico, tendo-se obtido 43 (86\%) respostas válidas, correspondentes aos professores, uma vez que os funcionários e encarregados de educação foram progressivamente se afastando do projeto. As respostas foram analisadas no software Ucinet 6.109 (Borgatti, Everett, \& Freeman, 2002), e os resultados foram processados pelo software Netdraw, permitindo representar graficamente as redes sociais.

Todos os projetos foram realizados conforme o plano definido e dentro dos prazos estabelecidos. Embora alguns projetos incluíssem tarefas a serem realizadas no ano letivo seguinte, as ações fundamentais foram completadas durante o mês de junho, três meses depois da sessão, tendo sido realizada uma reunião de coordenadores para apresentação dos resultados. Cada grupo entregou, nessa data, um pequeno relatório escrito. Após obtidos os gráficos relativos às redes, foram feitas entrevistas com participantes dos grupos, a fim de proporcionar uma melhor interpretação dos dados, em especial a respeito da atuação dos coordenadores das equipes. 


\section{Resultados}

Analisando separadamente cada uma das redes, verifica-se que a primeira aplicação (Figura 1) apresenta menos ligações que a segunda (Figura $2)$, quer diretas quer indiretas $(19 \%$ e $32 \%$ de todas as ligações possíveis, respectivamente). Analisando o grau de centralidade de cada nodo na rede (indicador do número de ligações do nodo na rede) pode ver-se que alguns nodos ocupam uma posição mais central na rede: 25MDP, 23MAC, 17JJ, 40TG e 1AJ, na primeira aplicação; 25MDP, 1AJ, 34PP, 13FS, 22MR e 7CC, na segunda. Esses elementos, coincidentes apenas em 25MDP e 1AJ, em ambos os momentos, identificam nodos em posição de intermediação (brokers), que tanto podem ser centrais, dizendo respeito ao grupo grande, como laterais e exclusivos do seu grupo. Esses brokers podem ser formais, se coincidem com os professores designados como facilitadores na segunda parte da sessão, ou informais, caso tenham surgido durante a realização dos projetos.

A Figura 1 traduz as respostas à primeira aplicação do questionário. O gráfico resulta da matriz de relações, em que cada participante escolhia aqueles com quem comunicava e, por sua vez, era escolhido pelos outros. As ligações visíveis não retratam a intensidade (tida em conta nas medidas e nos indicadores), mas apenas a existência de relações unívocas $(\rightarrow)$ ou recíprocas $(\leftrightarrow)$.

A Figura 2 diz respeito às respostas dadas na segunda aplicação do questionário, após a realização dos projetos. Como se pode ver nas figuras, a conexão evoluiu positivamente da primeira para a segunda aplicação, sendo interessante comparar os resultados da análise das redes antes e depois da realização dos projetos (Tabela 1).

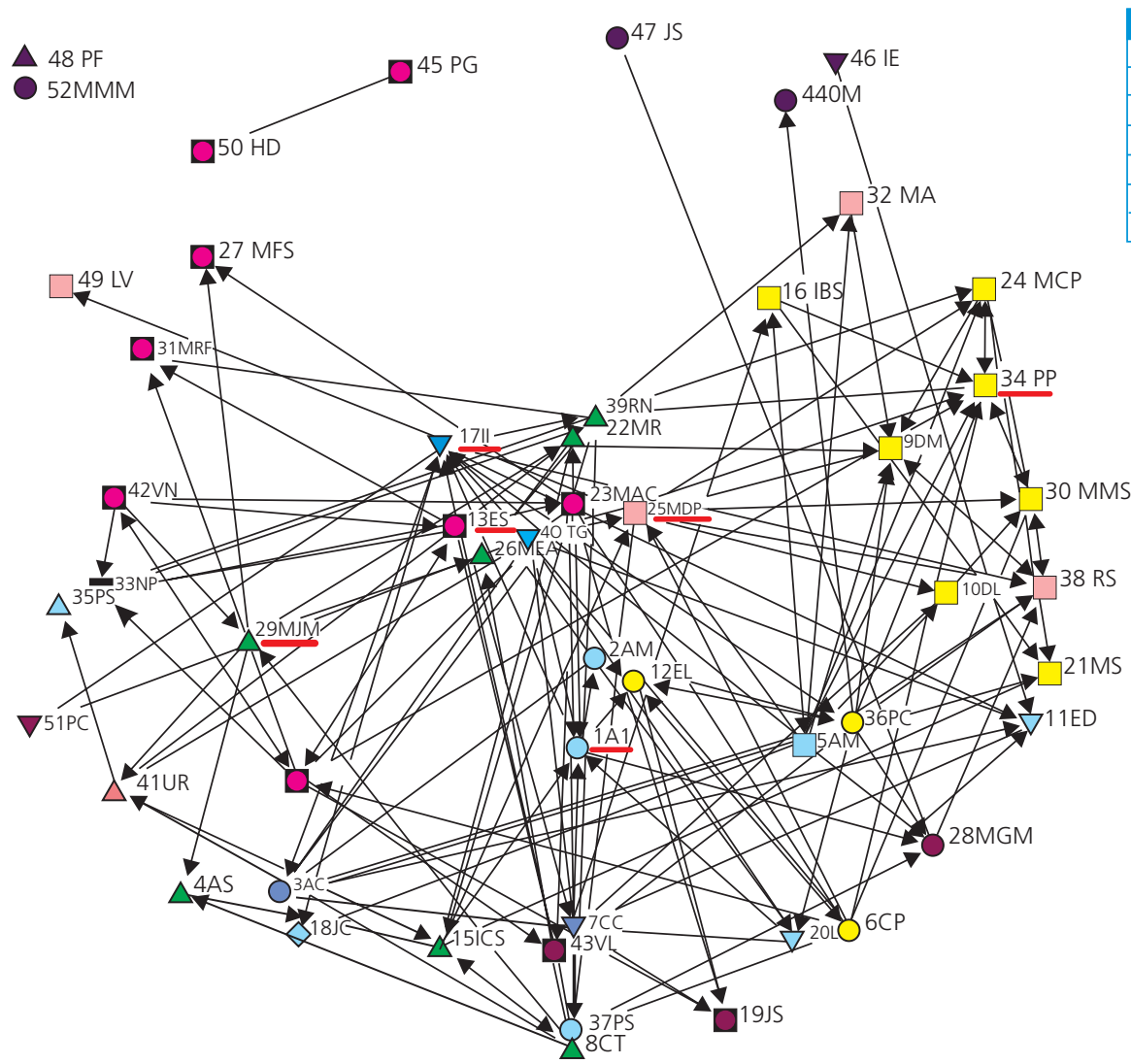

\begin{tabular}{|ll|}
\hline ESCOLA: & \\
\hline $\mathrm{S}^{\text {ta }}$ Bárbara & Círculo \\
\hline EB n-5 & Quadrado \\
\hline EB1 Lejana & Triâgulo $\mathrm{p}$ / cima \\
\hline EB1 Estoi & Triâgulo $\mathrm{p}$ / baixo \\
\hline EB1 Conceição & Círculo na caixa \\
\hline EB2-3 Emiliano Costa & Diamante \\
\hline EB1 Bordeira & Caixa \\
\hline
\end{tabular}

Figura 1. Gráfico do Netdraw (consideradas apenas as ligações de intensidade 3), relativo aos dados resultantes da sessão, mostrando a existência de relações dentro de cada grupo e escola (escolas representadas por figuras geométricas e grupos por cores). Cada nodo corresponde a um participante e, quando sublinhado, a um facilitador de grupo. 


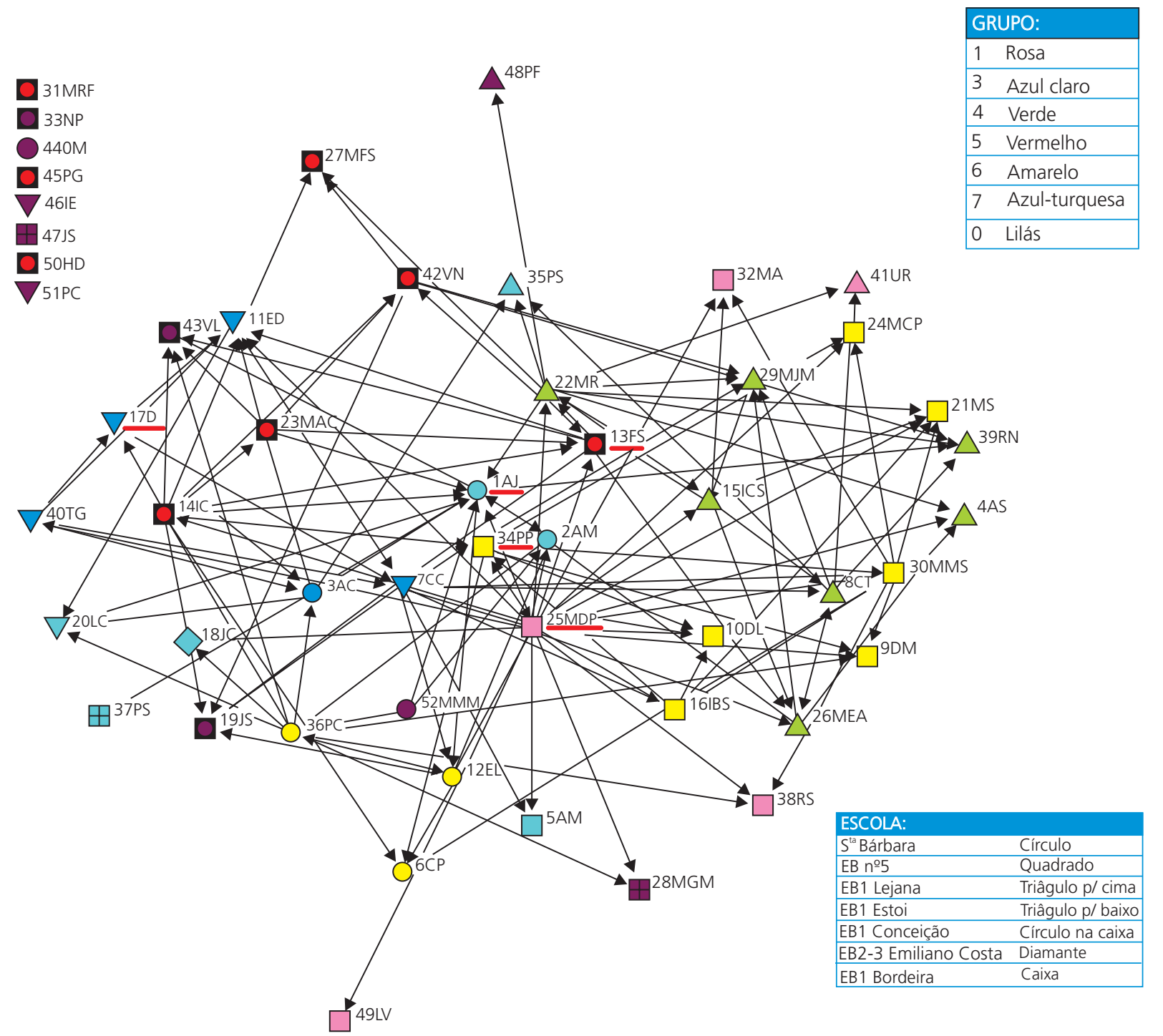

Figura 2. Gráfico do Netdraw (consideradas apenas as ligações de intensidade 3), relativo aos dados obtidos no final do projeto, mostrando a existência de relações dentro de cada grupo e escola (escolas representadas por figuras geométricas e grupos por cores). Cada nodo corresponde a um participante e, quando sublinhado, a um facilitador de grupo.

Tabela 1

Medidas de centralidade calculadas para toda a rede, antes e depois da realização dos projetos

\begin{tabular}{lccccc}
\hline \multirow{2}{*}{ Medidas } & \multicolumn{2}{c}{ Antes da execução } & & \multicolumn{2}{c}{ Depois da execução } \\
\cline { 2 - 5 } \cline { 5 - 6 } & Média & Desvio Padrão & & Média & Desvio Padrão \\
\hline Densidade & $19,8 \%$ & 0,9 & 0,6 & $29,2 \%$ & 1,0 \\
Distância Geodésica & 1,7 & 1,4 & & 1,7 & 0,6 \\
Intermediação Normalizada & $0,7 \%$ & & $1,1 \%$ & 2,1 \\
\hline
\end{tabular}

Embora os valores aqui apresentados, relativos ao momento anterior ao projeto, digam respeito à média dos valores de cada aplicação, pode-se constatar que a densidade da rede aumentou, apesar de ter se mantido a distância geodésica. Os valores mostram uma maior intermediação normalizada 
(normalized betweenness, ou nBetweeness), indicando que mais agentes dependem de outros para obter ou trocar informações. Verifica-se que o papel dos nodos se alterou durante o projeto, como revela a análise da medida normalizada de intermediação por nodo.

Nos grupos, a maioria dos nodos estão próximos uns dos outros, ou seja, a densidade é elevada e, por isso, torna-se interessante procurar clusters. No momento 1, os clusters encontrados foram: grupo 6 (EB 5 e Vale de Carneiros); grupo 4 (Lejana); e grupo 5 (Conceição e outras escolas). Os clusters foram formados por afinidades entre os elementos das várias escolas, ou seja, a possibilidade de a sessão fomentar dinâmicas de trabalho em escolas diferentes ditou a formação dos clusters. Também se constatou que os grupos foram formados aparentemente por dois critérios, urbano e rural, ou seja, as escolas do centro de Faro tiveram alguma preferência por trabalhar em conjunto, como Lejana e Vale de Carneiros, diferentemente das escolas rurais, principalmente a da Conceição.

No momento 2, os clusters encontrados resultaram acrescidos do grupo 3, envolvendo a escola de Santa Bárbara de Nexe e a de Vale de Carneiros; do grupo 4, formado por professores da escola da Lejana; e do grupo 7, com as escolas de Estoi, Santa Bárbara e outras. Também, enquanto no momento 1 a escola da Lejana se sobrepunha a vários grupos, no momento 2 ela se reparte por vários deles - donde se depreende o valor aglutinador da realização de projetos, em que o grupo se sobrepõe à escola.

A escolha dos temas, a concepção do plano de ação e a realização dos projetos para cada escola, justificaram a formação desses clusters. Essa realidade, de acordo com as entrevistas realizadas, deve-se essencialmente a dois fatores: a inexistência de uma cultura de agrupamento de escola e a proximidade geográfica. Ou seja, foi mais fácil trabalhar em equipe onde as pessoas estavam mais próximas. Assim, a informação disponível (quantitativa e qualitativa) permite concluir que o ganho relativo de clusters, comparando os momentos $1 \mathrm{e}$ 2 , deveu-se essencialmente à qualidade dos projetos

272 protagonizados, tanto pela escola da Lejana, como pela da Conceição e, em menor escala, pela EB 5, Vale Carneiros (grupo 3) e Santa Bárbara (grupo 7). Essas escolas desenvolveram um trabalho de acordo com o plano de ação definido, enquanto os demais grupos, apesar do ânimo inicial, esmoreceram um pouco. Em todo esse percurso, a ação dos coordenadores das equipes foi fundamental, como se verá a seguir.

Analisando as figuras, vê-se que alguns dos brokers iniciais não aparecem no momento 2 . Essa perda de brokers iniciais deveu-se, essencialmente, à dinâmica e aos propósitos que foram implementados pelos sucessivos grupos de trabalho. Daí que algumas das pessoas eleitas como bons coordenadores na sessão, foram perdendo esses atributos em detrimento de outros colegas no desenrolar do projeto final.

Analisando de forma concreta alguns casos:

- A docente 17 IJ, da escola básica de Estoi, designada como facilitadora, perdeu a característica inicial de broker central, passando a lateral (grupo). O grupo onde foi incluída inicialmente (grupo 3), escolheu como projeto final "a biblioteca vem à escola". O projeto foi desenvolvido pelo grupo a que pertencia a professora, conjuntamente com mais seis colegas, tendo-se verificado algumas dificuldades na fluidez de ideias e na organização do plano de ação, o que acabou por se repercutir no desempenho da professora como coordenadora. Acresce referir que a professora exerce as funções de coordenadora da escola de Estoi, onde é reconhecida pelos seus pares como uma ótima líder. Essa realidade seguramente influenciou a sua nomeação como facilitadora. Entretanto, a sua ação acabou por ser substituída pela 7CC.

- A professora 7CC, da escola de Estoi, foi reconhecida pelos seus pares em razão de seu contributo no desenvolvimento de toda a ação. Embora ela não tivesse sido referenciada como broker, passou a sê-lo.

- A professora 34PP, da escola de Vale Carneiros, é coordenadora de escola e foi a facilitadora nomeada no grupo 6 , não tendo sido cotada como broker no final da sessão. No entanto, desenvolveu um trabalho apreciado pelos colegas: não desistiu, animou os grupos, deu sugestões, fez 
questão de que os projetos avançassem e, enfim, justificou o título no final.

- A participante 25MDP, da escola de Vale Carneiros, é coordenadora de escola, foi facilitadora no grupo de trabalho e broker nos dois momentos. Os colegas a reconhecem como uma excelente coordenadora, sempre disposta a ajudar, positiva, gosta de concretizar ideias, nunca desanima, é muito sociável e foi incansável na procura de soluções para os problemas que iam surgindo.

- A professora 13FS, da escola da Conceição, foi facilitadora no grupo de trabalho final (grupo 5) e broker no momento 2. Os colegas referiram que animou a execução do projeto. Ela já tinha trabalhado em várias escolas e conhecia bem quase todos os colegas.

- A participante 22MR é coordenadora da escola da Lejana e não foi designada como facilitadora, aparecendo como broker no momento 2 . Referiu que teve o privilégio de estabelecer ligações com os vários professores dos diferentes grupos, pelo fato de ser coordenadora de escola. Tentou, na realização do projeto final, fazer um trabalho sério.

- A participante 1AJ é professora e coordenadora dos apoios educativos em duas escolas, Estoi e Santa Bárbara de Nexe. Na sessão foi facilitadora e apareceu como broker nos dois momentos. Por trabalhar em duas escolas, conhece vários professores. Os seus pares apreciaram o trabalho que desenvolveu, pois tentou levar a bom termo as ideias produzidas.

\section{Discussão}

Apesar de os projetos relativos aos vários grupos não terem sido realizados com o mesmo grau de finalização e empenho, ficou clara a eficácia demonstrada pelo método utilizado, não só em produzir novos projetos em pouco tempo e com grupos grandes, mas, sobretudo, pela capacidade de gerar o compromisso necessário para que eles fossem efetivamente executados. Associada à produção dos projetos, também ficou visível a transformação operada na rede social existente, bem como a importância da ação dos coordenadores, quer os designados, quer os que surgiram no desenrolar do processo.
E esse fato é tanto mais relevante quanto mais recente é o Agrupamento como unidade, já que as escolas constituintes desenvolviam apenas atividades e projetos de forma isolada. A justificação para essa realidade, de acordo com os entrevistados, deve-se ao fato de o Agrupamento ainda não ser entendido plenamente como tal, ou seja, a sua existência é ainda muito recente, não tendo havido tempo para consolidar devidamente os aspectos organizacionais.

O único projeto no qual todas as escolas estão envolvidas, simultaneamente, uma vez por ano, são as chamadas "Pinheiríadas". Trata-se de atividades desenvolvidas nas turmas por meio de várias provas, principalmente: (1) "Criatividade", consistente numa coreografia musical ou teatral; (2) "Quebra-Tolas", em que a disciplina de matemática tem um papel predominante; (3) "Desporto", em que as capacidades física-motoras são demonstradas e avaliadas; e, por último, (4) a prova de leitura, que premia os alunos com melhor desempenho linguístico. Depois existem atividades distribuídas pelas várias escolas, de caráter não transversal, como por exemplo, coletâneas de trabalhos, celebrações, atividades de Natal, Carnaval e Páscoa, atividades desportivas e uma grande variedade de atividades de final de ano.

Por isso se torna tão importante desenvolver projetos como o aqui experimentado e analisar não só os resultados dos projetos, mas, também, tudo o que se passa durante a sua execução, tal como feito aqui com as redes sociais, pois é no seguimento das atividades dos grupos que melhor se expressam as razões de sucesso ou insucesso dos planos realizados.

A melhoria dos métodos de análise das redes sociais poderá fornecer uma ferramenta importante para perceber melhor por que é que alguns projetos falham e outros têm sucesso, principalmente no que diz respeito à atuação dos facilitadores e brokers.

\section{Referências}

Ahuja, G. (2000). Collaboration networks, structural holes, and innovation: A longitudinal study. Administrative Science Quarterly, 45(3), 425-455. 
Basadur, M. (1987). Needed research in creativity for business and industrial applications. In S. G. Isaksen (Ed.), Frontiers of creativity research: Beyond the basics (pp.390-416). Buffalo: Bearly Limited.

Borgatti, S. P., Everett, M. G., \& Freeman, L. C. (2002). UCINET 6 for Windows: Software for social network analysis. Harvard: Analytical Technologies.

Bunker, B., \& Alban, B. (2006). The handbook of large group methods: Creating systemic change in organizations and communities. San Francisco: JosseyBass Publishers.

Burt, R. (1992). Structural holes. Cambridge: Harvard University Press.

Burt, R. (2004). Structural holes and good ideas. American Journal of Sociology, 110(2), 349-399. http://dx.doi. org/10.1086/421787

Fleming, L., \& Marx, M. (2006). Managing creativity in small-worlds. California Management Review, 48(4), 6-27.

Isaksen, S. G., \& Treffinger, D. J. (2004). Celebrating 50 Years of reflective practice: Versions of creative problem solving. The Journal of Creative Behavior, 38(4), 75-101.

Kastelle, T., \& Steen, J. (2010). Are small-world networks always best for innovation? Innovation: Management, Policy \& Practice, 12(1), 75-87. http://dx.doi.org/10. 5172/impp.12.1.75

Paulus, P. B., \& Brown, V. R. (2003). Enhancing ideational creativity in groups: Lessons from research. In P. B. Paulus \& B. A. Nijstad (Eds.), Group creativity: Innovation through collaboration. New York: Oxford University Press.

Puccio, G. J., Firestien, R. L., Coyle, C., \& Masucci, C. (2006). A review of the effectiveness of CPS
Training: A focus on workplace Issues. Creativity and Innovation Management, 15(1), 19-33. http://dx.doi. org/10.1111/j.1467-8691.2006.00366.X

Sousa, F., Mendes, A., \& Monteiro, I. (2012). Criatividade, educação artística e resolução colaborativa de problemas: um estudo de caso. Revista Trama Interdisciplinar, 3(1), 35-68.

Sousa, F., Monteiro, I., Gaspar, M., \& Castelão, P. (2016). Adapting large-group methods to civic forums: A way to improve citizenship and democracy. The International Journal of Organizational Innovation, 9(2), 1-18.

Sousa, F., Monteiro, I., \& Pellissier, R. (2009). Measures of effectiveness of creative problem solving in developing team creativity. Projectics/Proyéctica/Projectique, 3(3), 41-53. http://dx.doi.org/10.3917/proj.003.0041

Sousa, F., Monteiro, I., \& Pellissier, R. (2015). Adapting large-group methods to build small-world networks in higher education. Quality in Higher Education, 11, 66-87. http://dx.doi.org/10.7220/2345-0258.11.3

Sousa, F., Monteiro, I., Walton, A., \& Pissarra, J. (2014). Adapting creative problem solving to an organizational context: A study of its effectiveness with a student population. Creativity and Innovation Management, 23(3), 111-120. http://dx.doi.org/10.1111/caim.12070

Uzzi, B., \& Spiro, J. (2005). Collaboration and creativity: The small-world problem. American Journal of Sociology, 111(2), 447-504. http://dx.doi.org/10.1086/432782

Weisbord, M. (2012). Productive workplaces: Dignity, meaning and community in the 21st Century (3rd ed.). San Francisco: Jossey-Bass Publishers.

Recebido: novembro 6, 2017

Aprovado: dezembro 15, 2017 